\title{
Comparative evaluation of cancer stem cell markers in normal pancreas and pancreatic ductal adenocarcinoma
}

\author{
BARBARA VIZIO ${ }^{1}$, FRANCESCO A. MAURI ${ }^{2}$, ADRIANA PRATI $^{1}$, PRITESH TRIVEDI $^{2}$, ALICE GIACOBINO $^{3}$, \\ ANNA NOVARINO ${ }^{2}$, MARIA ANTONIETTA SATOLLI ${ }^{3}$, LIBERO CIUFFREDA $^{3}$, MICHELE CAMANDONA ${ }^{1}$, \\ GUIDO GASPARRI $^{1}$ and GRAZIELLA BELLONE ${ }^{1}$
}

${ }^{1}$ Department of Clinical Physiopathology, University of Turin, Turin, Italy; ${ }^{2}$ Department of Histopathology, Hammersmith Hospital, London, UK; ${ }^{3}$ Deparment of Medical Oncology, Azienda Ospedaliera Universitaria San Giovanni Battista, Molinette, Turin, Italy

Received February 23, 2011; Accepted April 20, 2011

DOI: 10.3892/or.2011.1461

\begin{abstract}
Chemoresistance and self-renewal of cancer stem cells (CSC), found in many tumors including pancreatic ductal adenocarcinoma (PDAC), are believed to underlie tumor mass regrowth. The distribution of cells carrying the putative stemcell markers CD133, Nestin, Notch1-4, Jagged1 and 2, ABCG2 and aldehyde dehydrogenase (ALDH1) was assessed immunohistochemically using PDAC and normal pancreas tissue microarrays. The immunoreactivity was semi-quantitatively graded against the normal pancreas and was correlated with the differentiation grade and disease stage. No statistical significant differences were found between normal pancreas and PDAC in the expression of Nestin, Notch1, 3 and 4, ABCG2 or ALDH1. Notch2 and Jagged1 and 2 expression were increased in PDAC. CD133-positive cells were abovenormal in PDAC, but the difference was not statistically significant. Nestin, Notch1-4, Jagged1, ABCG2 and ALDH1 immunostaining scores were not correlated with tumor grade or disease stage. CD133 and Notch2 expression was significantly inversely correlated with tumor grade, but not disease stage. Notch3 immunostaining positively correlated with tumor stage, but not with differentiation grade. Jagged2 protein expression correlated inversely with disease stage, but not with tumor grade. From the clinical standpoint, improved delineation of the tumor CSC signature, putatively responsible for tumor initiation and recurrence after initial response to chemotherapy, may offer novel therapeutic targets for this highly lethal cancer.
\end{abstract}

Correspondence to: Dr Graziella Bellone, Department of Clinical Physiopathology, Via Genova 3, 10126 Turin, Italy

E-mail: graziella.bellone@unito.it

Key words: pancreatic adenocarcinoma, cancer stem cells, CD133, Nestin, Notch, Jagged, ABCG2, aldehyde dehydrogenase, tissue microarray

\section{Introduction}

One of the major challenges in the treatment of pancreatic ductal adenocarcinoma (PDAC) is the frequent failure of chemotherapy (1). Poor response rates and short progressionfree intervals suggest that pancreatic cancer rapidly develops chemoresistance, or possesses it intrinsically. The lack of success with existing strategies underscores the importance of continued research efforts, in the hope of developing novel therapeutic strategies for the treatment of patients diagnosed with PDAC.

The cancer stem cell (CSC) theory (2) has given rise to a paradigm shift in how cancer biologists think about solid organ tumors. Underlying this increasingly-accepted concept is the hypothesis that, just as in organs and tissues, normal stem cells are at the apex of the hierarchical scheme that drives organogenesis, likewise cancer cells possessing the properties of stem cells may be key drivers of the complex machinery underlying tumorigenesis, since tumors themselves may function as complex organs.

Emerging data have shown that tumors are quite heterogeneous, and that they are composed of a small subset of distinct cancer cells, i.e. CSC, which are responsible for tumor initiation and propagation. These CSC, like their normal counterparts, possess the ability to self-renew, to produce differentiated progeny and, most notably, to survive adverse conditions in the tissue microenvironment (3). CSC were first discovered in the hematopoietic system (4) and have subsequently been identified in several solid tumors originating from the breast $(5)$, brain $(6)$, colon $(7,8)$, prostate $(9,10)$ and lung $(11)$. Recently, using a xenograft model, a subpopulation of highly tumorigenic cancer cells has been identified within human PDAC; these cells express the cell surface markers, CD44, CD24, and the epithelial-specific antigen (ESA), and display several features typically seen in stem cells, including the ability to self-renew, to generate differentiated progeny, and to recapitulate the phenotype of the tumor from which they were derived $(12,13)$.

In normal adult tissues, proper homeostatic tissue maintenance of stem cells is dependent on the integration of both 
cell-intrinsic and cell-extrinsic factors, and is achieved by the maintainance of a delicate balance between self-renewal and differentiation. The stem-cell niche has been envisaged to be a physiological microenvironment consisting of specialized cells that physically anchor the stem cell and provide the necessary factors to maintain its stemness (14). In light of the significant role played by the normal stem-cell niche in determining the cells' fate, it has been proposed that a CSC niche exists and that interactions with this tumor niche may play a similar role in specifying a self-renewing population of tumor cells.

Considerable effort is being expended in the search for markers of stem cells: collectively, these marker molecules appear to be involved in maintaining stemness, and in ensuring adhesion to the stem-cell niche; they may also be involved in cytoprotection (15). The phenotypic characterization of CSC is still debated. CD133, Nestin, Notch1-4, Jagged 1 and 2, ABCG2 and aldehyde dehydrogenase (ALDH1) are recognized as biomarkers that represent the stemness phenotype.

Since the feasibility of targeting the CSC niche therapeutically will at least in part depend on the degree of similarity between normal and CSC niches, the study used immunohistochemical methods to characterize the tissue distribution of these proteins, in formalin-fixed, paraffin-embedded human PDCA tissue, and to compare the findings with the distribution in normal human pancreas.

\section{Materials and methods}

PDAC tissue microarrays. Tumor specimens from 37 PDAC patients plus 6 samples of normal pancreatic tissue were analyzed. PDAC tissue microarrays (TMA) were obtained from Pantomics, (Richmond, CA) (duplicate cores per case: 20 cases of ductal adenocarcinoma and 3 cases of normal pancreatic tissue) and from US Biomax (Rockville, MD) (triplicate cores per case, 17 cases of ductal adenocarcinoma and 3 cases of normal pancreatic tissue). Patient characteristics are summarized in Table I. Tissues were fixed in formalin and embedded in paraffin. TMA were validated by hematoxylin and eosin staining.

Immunohistochemistry. Tissue fragments were melted into the acceptor paraffin block by heating the block for $30 \mathrm{~min}$ at $60^{\circ} \mathrm{C}$. Samples were deparaffinized in xylene and rehydrated in a graded series of alcohols; the antigen was then retrieved in Tris/EDTA buffer $(10 \mathrm{mmol} / \mathrm{l}$ Tris Base, $1 \mathrm{mmol} / \mathrm{l}$ EDTA, $\mathrm{pH}$ 9.0) using a pressure cooker. The sections were treated with a $3 \%$ solution of $\mathrm{H}_{2} \mathrm{O}_{2}$ for 5 min to inhibit endogenous peroxidase activity. After $1 \mathrm{~h}$ pre-incubation in a blocking buffer (5\% normal goat serum in phosphate-buffered saline) to prevent non-specific staining, the sections were incubated with primary antibodies (Table II), for $45 \mathrm{~min}$. The sections were then treated with the appropriate biotinylated secondary antibodies, followed by incubation with an avidin-biotin peroxidase complex solution, for $30 \mathrm{~min}$, and diaminobenzidine tetrahydrochloride as a chromogen. The slides were finally counterstained with Mayer's hematoxylin for $5 \mathrm{sec}$, dehydrated, and mounted in Clarion (Biomeda, Foster City, CA, USA).

Analysis of immunohistochemical expression patterns. The staining intensity was evaluated by a semi-quantitative
Table I. Clinical characteristics of the patients.

\begin{tabular}{lc}
\hline Pancreas ductal adenocarcinoma, N & 37 \\
Gender (male/female) & $15 / 22$ \\
Age (median, range) & $54(31-79)$ \\
Histological grading, N & \\
Well-differentiated (G1) & 7 \\
Moderately differentiated (G2) & 15 \\
Poorly differentiated (G3) & 15 \\
Stage (UICC staging system), N & \\
I & 11 \\
IIA & 10 \\
IIB & 9 \\
III & 0 \\
IV & 7 \\
Normal pancreas, N & 6 \\
Gender (male/female) & $3 / 3$ \\
Age (median, range) & $46(35-58)$ \\
\hline
\end{tabular}

method using the immunoreacting score (IRS) proposed by Remmele and Stegner (16) in which IRS = SI (staining intensity) $\mathrm{x}$ PP (\% of positive cells). SI was assigned as: 0 , negative; 1 , weak; 2 , moderate; 3 , strong. PP was assigned as: 0 , negative; $1,1-20 \%$ positive cells; $2,21-50 \%$ positive cells; $3,51-100 \%$ positive cells. Ten visual fields from different areas of each specimen were chosen at random for IRS evaluation, and the scores were averaged.

Statistical analysis. All results are expressed as median and range. The immunostaining scores of different stem cell markers in pancreatic carcinoma were compared with the scores in normal pancreas. Statistical analysis was performed using the non-parametric Mann-Whitney test to compare variables. The correlation between different parameters was analyzed using the non-parametric Spearman correlation coefficient; p-values of $<0.05$ were considered to indicate statistical significance. All statistical analyses were performed using the SigmaStat software (Jandel Scientific, San Rafael, CA, USA).

\section{Results}

Distribution of CD133, Nestin, Notch (1-4), Jaggedl and 2, $A B C G 2$ and ALDH1 in normal pancreas and PDAC. The distributions of CD133, Nestin, Notch (1-4), Jagged 1 and 2, ABCG2 and ALDH1 are summarized in Tables III and IV; representative staining profiles are in Fig. 1.

CD133. Immunoreactivity was observed in the center of the normal acini and in neoplastic ductal structures in a basilar pattern, defined by staining at the apical membrane of the cells. Staining was not seen in any specimen in the islets of Langerhans. Immunoreactivity to CD133 was retained in $29.7 \%$ (11/37) cases of PDCA, while expression was lost in $70.3 \%$ of cases $(26 / 37)$. In the positive cases, the area and intensity of expression varied along with the morphological heterogeneity of the tumor. No statistically-significant 
Table II. Antibodies used in immunohistochemistry.

\begin{tabular}{llll}
\hline Antigen & Antibody species & \multicolumn{1}{c}{ Manufacturer } & Dilution \\
\hline CD133/1 & Mouse monoclonal & Miltenyi BioTec, Bergisch Gladbach, Germany & $1: 50$ \\
Nestin & Mouse monoclonal & Santa Cruz Biotechnology, Santa Cruz, CA & $1: 50$ \\
Notch1 & Goat polyclonal & Santa Cruz Biotechnology & $1: 100$ \\
Notch2 & Rabbit polyclonal & Santa Cruz Biotechnology & $1: 500$ \\
Notch3 & Rabbit polyclonal & Santa Cruz Biotechnology & $1: 100$ \\
Notch4 & Rabbit polyclonal & Santa Cruz Biotechnology & $1: 100$ \\
Jagged1 & Goat polyclonal & Santa Cruz Biotechnology & $1: 500$ \\
Jagged2 & Rabbit polyclonal & Santa Cruz Biotechnology & $1: 100$ \\
ABCG2 & Mouse monoclonal & Chemicon International, Temecula, CA & $1: 30$ \\
ALDH1 & Rabbit monoclonal & Abgent, San Diego, CA & $1: 25$ \\
\hline
\end{tabular}

\section{Normal pancreas}
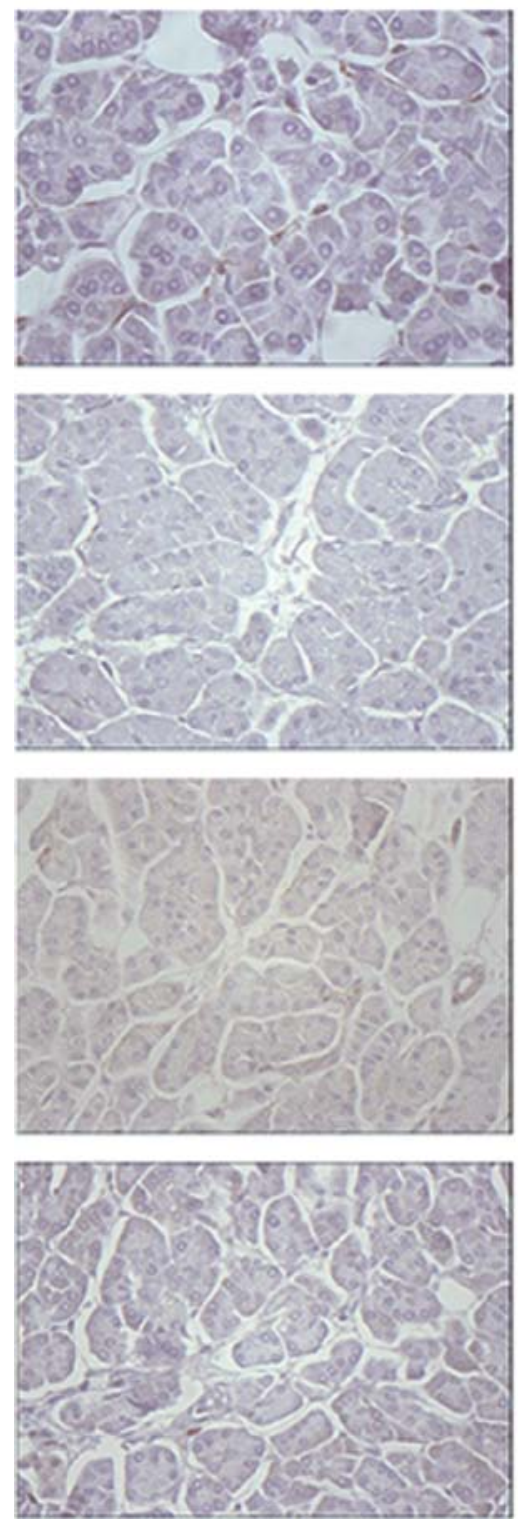

PDAC
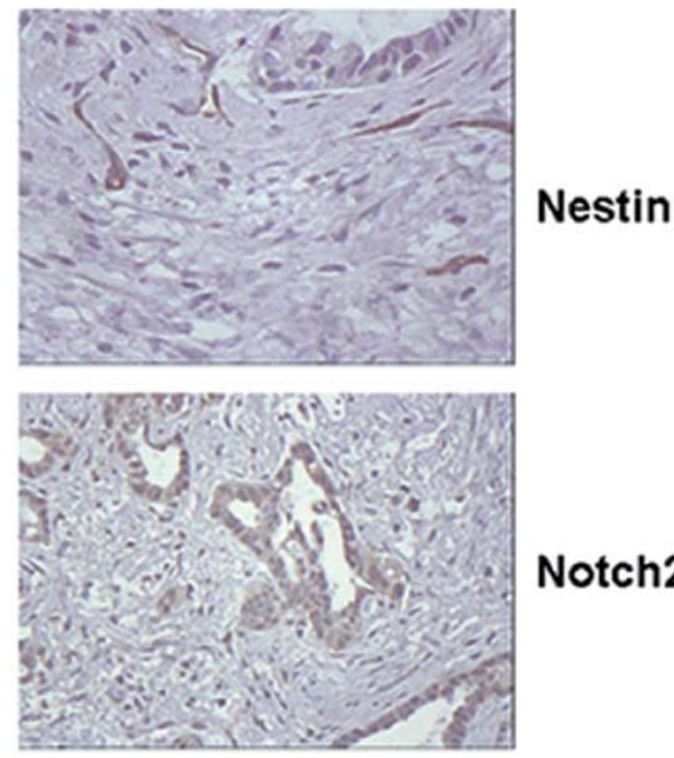

\section{Notch2}

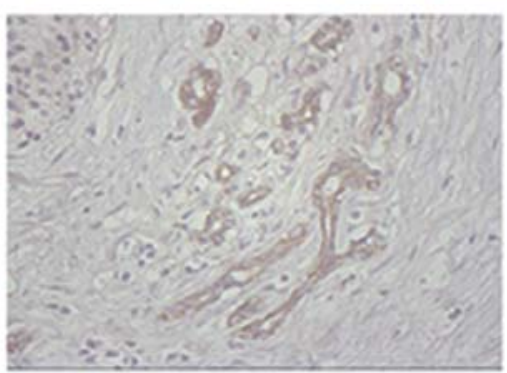

\section{Jagged1}

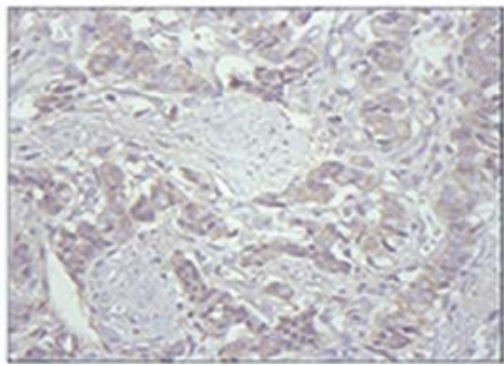

\section{Jagged2}

Figure 1. Differential expression of Nestin, Notch2, Jagged1 and Jagged2 proteins in normal pancreas and pancreatic ductal adenocarcinoma (PDAC) tissue specimens as determined by immunohistochemistry. Specimens are representative examples of 6 non-tumoral and 37 tumoral pancreas tissue samples (original magnification, $\mathrm{x} 250$ ). 
Table III. Summary of stem cell marker expression in normal pancreas and in pancreatic adenocarcinoma.

\begin{tabular}{|c|c|c|c|c|c|}
\hline \multirow{3}{*}{$\begin{array}{l}\text { Antigen } \\
\text { CD133 }\end{array}$} & \multicolumn{2}{|c|}{ Normal pancreas } & \multicolumn{3}{|c|}{ Pancreatic adenocarcinoma } \\
\hline & Localization & $\begin{array}{c}\text { IRS } \\
\text { median (range) }\end{array}$ & Localization & $\begin{array}{c}\text { IRS } \\
\text { median (range) }\end{array}$ & $\%(\#)$ \\
\hline & Acinar cells & $1(1-2)$ & Neoplastic ductal structures & $1 \quad(0.5-3)$ & $29.7(11 / 37)$ \\
\hline Nestin & $\begin{array}{l}\text { Capillary endothelial } \\
\text { cells and nerve fibers }\end{array}$ & $0(0-0.667)$ & $\begin{array}{l}\text { Capillary endothelial cells } \\
\text { and nerve fibers }\end{array}$ & $0.50(0-1.5)$ & $100(37 / 37)$ \\
\hline Notch1 & $\begin{array}{l}\text { Acinar and islets of } \\
\text { Langerhans cells }\end{array}$ & $3(0-4)$ & Neoplastic ductal structures & $(0-9)$ & $94.6(35 / 37)$ \\
\hline Notch2 & & 0 & Neoplastic ductal structures & $0.33(0-6)$ & $51.3(19 / 37)$ \\
\hline Notch3 & $\begin{array}{l}\text { Acinar and islets of } \\
\text { Langerhans cells }\end{array}$ & $2(0-6)$ & Neoplastic ductal structures & $(0-7.5)$ & $37.8(14 / 37)$ \\
\hline Notch4 & Islets of Langerhans cells & $0(0-2)$ & Islets of Langerhans cells & $0 \quad(0-2)$ & $100(37 / 37)$ \\
\hline Jagged 1 & Acinar cells & $0(0-1)$ & Neoplastic ductal structures & $0.75(0-3.7)$ & $40.5(15 / 37)$ \\
\hline Jagged 2 & & 0 & $\begin{array}{l}\text { Non-neoplastic exocrine } \\
\text { pancreas adjacent to ductal } \\
\text { adenocarcinoma cells }\end{array}$ & $1 \quad(0-6)$ & $67.6(25 / 37)$ \\
\hline $\mathrm{ABCG} 2$ & Acinar cells & $0(0-0.33)$ & Neoplastic ductal structures & $(0-1)$ & $5.4 \quad(2 / 37)$ \\
\hline ALDH1 & $\begin{array}{l}\text { Acinar and islets of } \\
\text { Langerhans cells }\end{array}$ & $1.5(1-3)$ & Neoplastic ductal structures & $(0-4)$ & $29.7(11 / 37)$ \\
\hline
\end{tabular}

Table IV. Correlation among the immunoreacting score of different stem cell markers, differentiation grading and disease staging.

\begin{tabular}{lccccc}
\hline & \multicolumn{2}{c}{ Differentiation grade } & & \multicolumn{2}{c}{ Disease stage } \\
\cline { 2 - 3 } Markers & $\mathrm{r}^{\mathrm{a}}$ & $\mathrm{p}$ & & $\mathrm{r}$ & $\mathrm{p}$ \\
\hline CD133 & -0.357 & 0.030 & & -0.102 & 0.545 \\
Nestin & 0.193 & 0.250 & & 0.069 & 0.682 \\
Notch1 & 0.0001 & 0.999 & & 0.046 & 0.786 \\
Notch2 & 0.482 & 0.003 & & 0.108 & 0.521 \\
Notch3 & 0.103 & 0.544 & & 0.373 & 0.023 \\
Notch4 & -0.260 & 0.120 & & 0.147 & 0.384 \\
Jagged1 & -0.013 & 0.937 & & 0.273 & 0.102 \\
Jagged2 & -0.010 & 0.950 & & -0.456 & 0.005 \\
ABCG2 & -0.172 & 0.308 & & -0.148 & 0.380 \\
ALDH1 & 0.245 & 0.143 & & 0.282 & 0.090 \\
\hline
\end{tabular}

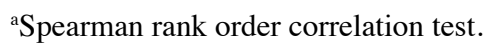

difference was detected in the IRS between the normal pancreas and positive PDAC [median (range): 1 (1-2) vs. 1 $(0.5-3), \mathrm{p}=0.186)]$.

Nestin. No immunostaining was seen in acinar cells nor in islets of Langerhans of normal pancreas nor in neoplastic ductal cells. Nestin was identified in some pancreatic capillary endothelial cells and in nerve fibers within the islets in normal pancreas, and in either invading cells or in cells adjacent to cancer cells in all PDAC cases. Significant differences in IRS, calculated in positive cells, were observed between normal and tumor pancreas (median (range) 0 (0-0.667) vs. 0.5 (0-1.5), $\mathrm{p}=0.006)$.

Notchl. In normal pancreas, positive cells were identified in the acini and also in the cells of the islets of Langerhans. Notch1 expression was identified in $94.6 \%$ of PDAC specimens (35/37). Immunostaining was observed in the cytoplasm of neoplastic ductal structures. No statistically-significant difference was detected in IRS between normal pancreas and PDAC; median (range): 3 (0-4) vs. 3 (0-9), p=0.186).

Notch2. No immunostaining was seen in normal pancreas (acinar cells nor islets of Langerhans). Notch2 expression in PDAC was identified in $51.3 \%$ of specimens (19/37). Immunostaining was observed in the cytoplasm of neoplastic ductal structures.

Notch3. In the normal pancreas, Notch3 expression was identified in the cytoplasm of cells of the islets of Langerhans and acinar cells, with immunostaining intensity being stronger in the latter. Notch3 expression was found in $37.8 \%$ of PDAC specimens (14/37). Cytoplasmic and nuclear immunostaining was identified in neoplastic ductal structures. No significant differences in IRS between normal and positive PDAC were observed; median (range): 2 (0-6) vs. 2 (0-7.5), p=0.385).

Notch4. In normal pancreas, Notch4-positive cells were only identified in the cells of the islets of Langerhans. No positive acinar cells were seen. Expression was not identified in any PDAC specimens.

Jagged1. In normal pancreas, Jagged1-positive cells were focally identified in the acini, whereas cells of the islets of 
Langerhans were negative. Expression was identified in $40.5 \%$ of PDAC specimens (15/37). Immunostaining was observed in the cytoplasm of neoplastic ductal structures. A statisticallysignificant increase in IRS was found in positive PDAC vs. normal pancreas. The median (range) was $0.750(0-3.7)$ in PDAC vs. 0 (0-1) in normal ( $\mathrm{p}=0.040)$.

Jagged2. In normal pancreas, immunostaining for Jagged2 was negative in both exocrine and endocrine components. Expression was identified in $67.6 \%$ of PDAC specimens (25/37). Immunostaining was observed in the cytoplasm of neoplastic ductal structures. Interestingly, acinar cells were positive in non-neoplastic exocrine pancreas adjacent to ductal adenocarcinoma cells; IRS median range: 1 (0-6).

$A B C G 2$. Weak cytoplasmic staining was focally seen in the acinar cells of the normal pancreas. Occasional ABCG2positive cells were identified in $5.4 \%$ of PDAC specimens (2/37). Immunostaining was identified in the tumor-cell cytoplasm. Normal endocrine islets were negative. Similar IRS values were observed between normal and PDAC specimens; median (range): 0 (0-0.33) vs. $0(0-1), \mathrm{p}=0.919$.

$A L D H I$. In normal pancreas, ALDH1-positive cells were focally identified in the acini. Expression was identified in $29.7 \%$ of PDAC specimens. Immunostaining was observed in the cytoplasm of neoplastic ductal structures. Cells of the islets of Langerhans were also positive, particularly in the areas containing $\beta$-cells (insulin production). No significant differences were found between normal and positive tumor pancreas specimens; median (range): 1.5 (1-3) vs. 1 (0-4), $\mathrm{p}=0.125$.

Correlation among stem cell marker expression, differentiation grading and disease staging. The correlation among IRS of different stem cell markers evaluated in tumor tissues, differentiation grading, and disease staging, was calculated by the Spearman rank order correlation test (Table IV). CD133 protein expression was inversely and significantly correlated with tumor differentiation grading $(\mathrm{p}=0.03)$, but not with tumor stage ( $\mathrm{p}=0.545)$. Notch1, Notch4, Jagged1, ABCG2 and ALDH1 IRS were not associated with either tumor differentiation grade ( $\mathrm{p}=0.999, \mathrm{p}=0.937, \mathrm{p}=0.120, \mathrm{p}=0.308, \mathrm{p}=0.143$, respectively) or tumor stage $(\mathrm{p}=0.786, \mathrm{p}=0.384, \mathrm{p}=0.102, \mathrm{p}=0.380, \mathrm{p}=0.090$, respectively). Notch 2 protein expression was positively correlated with differentiation grade $(p=0.003)$, but not with tumor stage $(\mathrm{p}=0.521)$. A positive correlation was found between Notch3 immunostaining and tumor stage $(\mathrm{p}=0.023)$, but not with differentiation grade $(\mathrm{p}=0.544)$. By contrast, Jagged2 protein expression was inversely correlated with tumor stage $(\mathrm{p}=0.005)$, but was not correlated with tumor differentiation grade $(\mathrm{p}=0.950)$.

\section{Discussion}

It has recently been reported that, in addition to initiating and sustaining tumor growth, CSC may also mediate cancer drug resistance, relapse and metastasis; this has been found to occur in several human malignancies, including PDAC. Nevertheless, little is known about the expression of CSC markers in situ, especially in relation with normal pancreas and the tumor's grade of malignancy. To address this problem, we investigated the concomitant expression of ten proteins:
CD133, Nestin, Notch1, Notch2, Notch3, Notch4, Jagged1, Jagged2, ABCG2 and ALDH1, which are the most widelyaccredited markers for identification of CSC.

The expression of CD133 (human prominin-1), originally identified as a cell-surface antigen present in $\mathrm{CD} 34^{+}$hematopoietic stem cells, is one criterion which has been used to identify putative CSC in solid tumors, such as brain $(6,17)$, lung (18), skin, melanoma (19), prostate (10), kidney (20) colon $(7,8)$ and liver $(21)$.

In our series of cases, CD133 expression was increased in PDAC vs. normal pancreatic epithelial cells, although statistical significance was not achieved. Moreover, we found this marker to be inversely associated with tumor differentiation grade, in line with studies reporting both the presence of CD133 in different types of stem cells and in several solid tumors, and its down-regulated expression in differentiated cells (22). In particular, it has been demonstrated that CD133 is a marker of putative pancreatic progenitor cells during embryogenesis (23). The localization of the CD133 marker on the apical cell surface, in both normal and tumor tissues, suggests its involvement in the mechanisms influencing cell polarity, migration and interaction of stem cells with neighboring cells and/or the extracellular matrix, although experimental data are not yet available. Side populations of cells with stem-cell characteristics, isolated from human pancreatic carcinoma cells, show significantly higher levels of mRNA expression for CD133 and have high resistance to gemcitabine treatment, a chemotherapeutic drug currently used in clinical settings against aggressive PDAC (24).

Nestin, originally described as a neuronal stem cell/ progenitor cell marker during central nervous system development $(25,26)$, was initially described in the adult pancreas as a specific marker of a cell subpopulation having a possible stem-cell function (27).

In agreement with other reports $(28,29)$, the immunohistochemical studies to characterize Nestin expression in the normal pancreas and in PDAC showed that Nestin was localized in a few capillary endothelial cells and nerve fibers within the islets of normal pancreatic tissues and in numerous capillary endothelial cells and nerve fibers invading the tumor area in PDAC. Despite the Nestin cellular localization revealed by immunohistochemistry, lineage-tracing experiments indicate that the cells derived from Nestin-expressing progenitor cells are mostly exocrine cells $(30,31)$. Moreover, in rodents, Nestin-expressing cells contribute to the regenerative capacity of the exocrine pancreas, after partial pancreatectomy and during recovery from acute pancreatitis (32). In a mouse model, it has been demonstrated that activation of oncogenic K-ras in the Nestin cell lineage is sufficient to initiate pancreatic intraepithelial neoplasia lesions (PanINs), putative precursors to PDAC (33), suggesting that these cells may be the elusive progenitor population from among which PDAC arises.

During development of the pancreas, differentiation of epithelial precursors is tightly regulated by Notch signaling, a highly conserved pathway known to regulate cell-fate decisions in a variety of organisms (34). In vertebrates there are four Notch transmembrane receptors, Notch 1, 2, 3 and 4, whose activities are controlled by the family ligands, Delta-like and Jagged (Jagged1 and Jagged2) (35). Moreover, mechanistically, 
increased Notch signaling is associated with chemoresistance, and with the epithelial-mesenchymal transition (EMT) characteristic of pancreatic carcinoma cells (36).

Among the four members of the Notch protein family, we found that Notch1 and Notch4 were similarly expressed in normal and tumor tissues, and were not correlated to either tumor differentiation grade or stage. Interestingly, though, cytoplasmic Notch 2 expression was identified in approximately $50 \%$ of PDAC cells, but not in their normal counterparts, and there was a positive correlation with the grade of tumor differentiation. It has been reported that immortalized human pancreatic Nestin-expressing cells, after transfection with cDNA of the catalytic subunit of telomerase (hTERT-HPNE), have properties identical to those of the intermediary cells observed during acinar-to-ductal metaplasia (37), and that unlike their native counterparts they express Notch2 (38). By contrast, Notch3 protein was not differentially expressed in quantitative terms in PDAC vs. normal pancreas. However, in tumors, its expression was correlated with disease stage, suggesting that Notch3 is mechanistically linked with a more malignant phenotype.

Notch signaling is activated through the interaction of Notch receptors with Delta-like and Jagged ligands on neighboring cells (39). It consists of two cleavages, occurring at the extracellular side, followed by a third cleavage that liberates the intracellular Notch receptor domain, which is translocated to the cell nucleus $(40,41)$, where it regulates the balance between cell differentiation and stem cell proliferation, during the development of numerous tissues, including the pancreas $(34,42)$. It is likely that this latter form participates in neoplastic cell transformation in several organs, such as the cervix, uteri, lung, breast, nerve tissue and also in the pancreas (43-47). However, the cases of staining in PDAC that we found were uniformly cytoplasmic, with no nuclear Notch2 and Notch3 being observed in any case; it is thus likely that tumors expressing nuclear Notch 2 and Notch 3 had been found to be non-resectable.

We found that both Jagged1 and Jagged2 ligands were more strongly expressed in tumor lesions that in normal tissue counterparts. In our series of tissues, Notch 2 and Notch3 receptors were up-regulated in the tumor specimens. Thus, Notch can be reactivated in pancreatic tumors and may potentially be linked to stemness acquisition and to EMT (36).

CSC have been hypothesized to be resistant to conventional chemotherapy and radiation therapy, and are thought to be the culprits behind cancer metastasis and recurrence after clinical remission. The ABC transporter family ABCG2 functions as a high-capacity drug transporter with wide substrate specificity (48). Expression of ABCG2 is observed not only in adult stem cells but also in primary cancer cells and cell lines, where it confers a multidrug resistant phenotype, although its precise physiological role in stem cells is still unclear (49). In our study, we identified ABCG2-positive cells only occasionally and in only a few PDAC patients, with IRS values similar to those of normal pancreas, in agreement with what has been reported by König et al (50).

ALDH1 is part of a group of $\mathrm{NAD}(\mathrm{P})^{+}$-dependent enzymes involved in oxidizing a wide variety of aldehydes into their corresponding carboxylic acids (51). ALDH1 activity identifies normal stem cells and tumor-initiating cells (i.e. CSC) in several human malignancies, where it seems to play an important role in drug resistance, cell proliferation, differentiation and response to oxidative stress (52-54). It is reported that ALDH1 is required for development of the pancreas during mouse embryogenesis, and is associated with tumorigenic pancreatic cancer cells both in vitro and in vivo. We found that the majority of primary tumor specimens lacked expression of ALDH1-positive cells (70\%), while this protein was widely expressed in normal pancreas specimens. This is in contrast with a recent study (55) that found high expression of ALDH1 in PDCA. This discrepancy might be due to variability in tumor sampling, or it could be that tumors are phenotypically and functionally distinct in terms of CSC.

Although an optimal enumeration technique has not yet been determined, and consensus has not yet been reached concerning the phenotypic definition of CSC, clinical studies assessing these cells in cancer patients are increasingly being reported. However, inter-laboratory variability, resulting from doubt over the definition of CSC, and different technical methods (e.g., antigen retrieval and detection methods) used in the different studies, make comparison among different reports difficult.

It is clear that additional research is needed to increase our understanding of the molecular machinery underlying the regulation of cell self-renewal and resistance to chemotherapy and radiation in pancreatic CSC, and that much is yet to be learned about the intricacies of the pancreatic cancer microenvironment and its causes. However, our study points to a possible different pattern of frequency and localization of CSC markers in PDAC vs. normal pancreas, in particular concerning the Notch pathway and Jagged ligands. Improved delineation of such a signature would be very important to develop targeted combination therapies for selective elimination of CSC, having minimal toxicity to normal stem cells, which would likely benefit patients suffering from this difficult to treat disease.

\section{Acknowledgements}

This study was supported by grants from the Piedmontese Regional Government to G.B.

\section{References}

1. Sultana A, Smith CT, Cunningham D, Starling N, Neoptolemos JP and Ghaneh P: Meta-analyses of chemotherapy for locally advanced and metastatic pancreatic cancer. J Clin Oncol 25: 2607-2615, 2007.

2. Reya T, Morrison SJ, Clarke MF and Weissman IL: Stem cells, cancer, and cancer stem cells. Nature 414: 105-111, 2001.

3. Bissell MJ and LaBarge MA: Context, tissue plasticity, and cancer: are tumor stem cells also regulated by the microenvironment? Cancer Cell 7: 17-23, 2005.

4. Bonnet D and Dick JE: Human acute myeloid leukemia is organized as a hierarchy that originates from a primitive hematopoietic cell. Nat Med 3: 730-737, 1997.

5. Al-Hajj M, Wicha MS, Benito-Hernandez A, Morrison SJ and Clarke MF: Prospective identification of tumorigenic breast cancer cells. Proc Natl Acad Sci USA 100: 3983-3988, 2003.

6. Singh SK, Hawkins C, Clarke ID, Squire JA, Bayani J, Hide T, Henkelman RM, Cusimano MD and Dirks PB: Identification of human brain tumour initiating cells. Nature 432: 396-401, 2004. 
7. O'Brien CA, Pollett A, Gallinger S and Dick JE: A human colon cancer cell capable of initiating tumour growth in immunodeficient mice. Nature 445: 106-110, 2007.

8. Ricci-Vitiani L, Lombardi DG, Pilozzi E, Biffoni M, Todaro M, Peschle $\mathrm{C}$ and De MR: Identification and expansion of human colon-cancer-initiating cells. Nature 445: 111-115, 2007.

9. Collins AT and Maitland NJ: Prostate cancer stem cells. Eur J Cancer 42: 1213-1218, 2006.

10. Miki J, Furusato B, Li H, Gu Y, Takahashi H, Egawa S, Sesterhenn IA, McLeod DG, Srivastava S and Rhim JS: Identification of putative stem cell markers, CD133 and CXCR4, in hTERT-immortalized primary nonmalignant and malignant tumor-derived human prostate epithelial cell lines and in prostate cancer specimens. Cancer Res 67: 3153-3161, 2007.

11. Eramo A, Lotti F, Sette G, Pilozzi E, Biffoni M, Di VA, Conticello C, Ruco L, Peschle C and De MR: Identification and expansion of the tumorigenic lung cancer stem cell population. Cell Death Differ 15: 504-514, 2008.

12. Li C, Heidt DG, Dalerba P, Burant CF, Zhang L, Adsay V, Wicha M, Clarke MF and Simeone DM: Identification of pancreatic cancer stem cells. Cancer Res 67: 1030-1037, 2007.

13. Hermann PC, Huber SL, Herrler T, Aicher A, Ellwart JW, Guba M, Bruns CJ and Heeschen C: Distinct populations of cancer stem cells determine tumor growth and metastatic activity in human pancreatic cancer. Cell Stem Cell 1: 313-323, 2007.

14. Schofield R: The relationship between the spleen colonyforming cell and the haemopoietic stem cell. Blood Cells 4: 7-25, 1978.

15. Soltysova A, Altanerova V and Altaner C: Cancer stem cells. Neoplasma 52: 435-440, 2005.

16. Remmele W and Stegner HE: Recommendation for uniform definition of an immunoreactive score (IRS) for immunohistochemical estrogen receptor detection (ER-ICA) in breast cancer tissue. Pathologe 8: 138-140, 1987 (In German).

17. Singh SK, Clarke ID, Terasaki M, Bonn VE, Hawkins C, Squire J and Dirks PB: Identification of a cancer stem cell in human brain tumors. Cancer Res 63: 5821-5828, 2003.

18. Donnenberg VS, Landreneau RJ and Donnenberg AD: Tumorigenic stem and progenitor cells: implications for the therapeutic index of anti-cancer agents. J Control Release 122: 385-391, 2007.

19. Monzani E, Facchetti F, Galmozzi E, Corsini E, Benetti A, Cavazzin C, Gritti A, Piccinini A, Porro D, Santinami M, Invernici G, Parati E, Alessandri G and La Porta CA: Melanoma contains CD133 and ABCG2 positive cells with enhanced tumourigenic potential. Eur J Cancer 43: 935-946, 2007.

20. Bussolati B, Bruno S, Grange C, Buttiglieri S, Deregibus MC Cantino D and Camussi G: Isolation of renal progenitor cells from adult human kidney. Am J Pathol 166: 545-555, 2005.

21. Ma S, Chan KW, Hu L, Lee TK, Wo JY, Ng IO, Zheng BJ and Guan XY: Identification and characterization of tumorigenic liver cancer stem/progenitor cells. Gastroenterology 132: 2542-2556, 2007.

22. Kania G, Corbeil D, Fuchs J, Tarasov KV, Blyszczuk P, Huttner WB Boheler KR and Wobus AM: Somatic stem cell marker prominin-1/CD133 is expressed in embryonic stem cell-derived progenitors. Stem Cells 23: 791-804, 2005.

23. Hori Y, Fukumoto M and Kuroda Y: Enrichment of putative pancreatic progenitor cells from mice by sorting for prominin1 (CD133) and platelet-derived growth factor receptor beta. Stem Cells 26: 2912-2920, 2008

24. Wang YH, Li F, Luo B, Wang XH, Sun HC, Liu S, Cui YQ and $\mathrm{Xu}$ XX: A side population of cells from a human pancreatic carcinoma cell line harbors cancer stem cell characteristics. Neoplasma 56: 371-378, 2009.

25. Lendahl U, Zimmerman LB and McKay RD: CNS stem cells express a new class of intermediate filament protein. Cell 60 : $585-595,1990$

26. Yang J, Cheng L, Yan Y, Bian W, Tomooka Y, Shiurba R and Jing N: Mouse nestin cDNA cloning and protein expression in the cytoskeleton of transfected cells. Biochim Biophys Acta 1520: 251-254, 2001

27. Hunziker E and Stein M: Nestin-expressing cells in the pancreatic islets of Langerhans. Biochem Biophys Res Commun 271: 116-119, 2000.

28. Treutelaar MK, Skidmore JM, Dias-Leme CL, Hara M, Zhang L, Simeone D, Martin DM and Burant CF: Nestin-lineage cells contribute to the microvasculature but not endocrine cells of the islet. Diabetes 52: 2503-2512, 2003.
29. Kawamoto M, Ishiwata T, Cho K, Uchida E, Korc M, Naito Z and Tajiri T: Nestin expression correlates with nerve and retroperitoneal tissue invasion in pancreatic cancer. Hum Pathol 40: 189-198, 2009.

30. Delacour A, Nepote V, Trumpp A and Herrera PL: Nestin expression in pancreatic exocrine cell lineages. Mech Dev 121: 3-14, 2004

31. Esni F, Stoffers DA, Takeuchi T and Leach SD: Origin of exocrine pancreatic cells from nestin-positive precursors in developing mouse pancreas. Mech Dev 121: 15-25, 2004.

32. Ishiwata T, Kudo M, Onda M, Fujii T, Teduka K, Suzuki T, Korc $\mathrm{M}$ and Naito Z: Defined localization of nestin-expressing cells in L-arginine-induced acute pancreatitis. Pancreas 32: 360-368, 2006

33. Kim SY, Lee SH, Kim BM, Kim EH, Min BH, Bendayan M and Park IS: Activation of nestin-positive duct stem (NPDS) cells in pancreas upon neogenic motivation and possible cytodifferentiation into insulin-secreting cells from NPDS cells. Dev Dyn 230: 1-11, 2004.

34. Artavanis-Tsakonas S, Rand MD and Lake RJ: Notch signaling: cell fate control and signal integration in development. Science 284: 770-776, 1999.

35. Callahan R and Egan SE: Notch signaling in mammary development and oncogenesis. J Mammary Gland Biol Neoplasia 9: $145-163,2004$

36. Wang Z, Li Y, Kong D, Banerjee S, Ahmad A, Azmi AS, Ali S, Abbruzzese JL, Gallick GE and Sarkar FH: Acquisition of epithelial-mesenchymal transition phenotype of gemcitabineresistant pancreatic cancer cells is linked with activation of the notch signaling pathway. Cancer Res 69: 2400-2407, 2009.

37. Parsa I, Longnecker DS, Scarpelli DG, Pour P, Reddy JK and Lefkowitz M: Ductal metaplasia of human exocrine pancreas and its association with carcinoma. Cancer Res 45: 1285-1290, 1985.

38. Lee KM, Yasuda H, Hollingsworth MA and Ouellette MM: Notch 2-positive progenitors with the intrinsic ability to give rise to pancreatic ductal cells. Lab Invest 85: 1003-1012, 2005.

39. Mumm JS and Kopan R: Notch signaling: from the outside in. Dev Biol 228: 151-165, 2000

40. De Strooper B, Annaert W, Cupers P, Saftig P, Craessaerts K, Mumm JS, Schroeter EH, Schrijvers V, Wolfe MS, Ray WJ, Goate A and Kopan R: A presenilin-1-dependent gammasecretase-like protease mediates release of Notch intracellular domain. Nature 398: 518-522, 1999.

41. Struhl G and Greenwald I: Presenilin is required for activity and nuclear access of Notch in Drosophila. Nature 398: 522-525, 1999.

42. Miyamoto Y, Maitra A, Ghosh B, Zechner U, Argani P, Iacobuzio-Donahue CA, Sriuranpong V, Iso T, Meszoely IM, Wolfe MS, Hruban RH, Ball DW, Schmid RM and Leach SD: Notch mediates TGF alpha-induced changes in epithelial differentiation during pancreatic tumorigenesis. Cancer Cell 3: 565-576, 2003

43. Apelqvist A, Li H, Sommer L, Beatus P, Anderson DJ, Honjo T, Hrabe de Angelis M, Lendahl U and Edlund H: Notch signalling controls pancreatic cell differentiation. Nature 400: 877-881, 1999.

44. Radtke F and Raj K: The role of Notch in tumorigenesis: oncogene or tumour suppressor? Nat Rev Cancer 3: 756-767, 2003.

45. Stylianou S, Clarke RB and Brennan K: Aberrant activation of notch signaling in human breast cancer. Cancer Res 66: 1517-1525, 2006.

46. Nickoloff BJ, Osborne BA and Miele L: Notch signaling as a therapeutic target in cancer: a new approach to the development of cell fate modifying agents. Oncogene 22: 6598-6608, 2003.

47. Buchler P, Gazdhar A, Schubert M, Giese N, Reber HA Hines OJ, Giese T, Ceyhan GO, Muller M, Buchler MW and Friess H: The Notch signaling pathway is related to neurovascular progression of pancreatic cancer. Ann Surg 242: 791-800, 2005

48. Glavinas H, Krajcsi P, Cserepes J and Sarkadi B: The role of $\mathrm{ABC}$ transporters in drug resistance, metabolism and toxicity. Curr Drug Deliv 1: 27-42,2004.

49. Haimeur A, Conseil G, Deeley RG and Cole SP: The MRP-related and BCRP/ABCG2 multidrug resistance proteins: biology, substrate specificity and regulation. Curr Drug Metab 5: 21-53, 2004.

50. Konig J, Hartel M, Nies AT, Martignoni ME, Guo J, Buchler MW, Friess $\mathrm{H}$ and Keppler D: Expression and localization of human multidrug resistance protein (ABCC) family members in pancreatic carcinoma. Int J Cancer 115: 359-367, 2005. 
51. Yoshida A, Rzhetsky A, Hsu LC and Chang C: Human aldehyde dehydrogenase gene family. Eur J Biochem 251: 549-557, 1998.

52. Huang EH, Hynes MJ, Zhang T, Ginestier C, Dontu G, Appelman H, Fields JZ, Wicha MS and Boman BM: Aldehyde dehydrogenase 1 is a marker for normal and malignant human colonic stem cells (SC) and tracks SC overpopulation during colon tumorigenesis. Cancer Res 69: 3382-3389, 2009.

53. Ginestier C, Hur MH, Charafe-Jauffret E, Monville F, Dutcher J, Brown M, Jacquemier J, Viens P, Kleer CG, Liu S, Schott A, Hayes D, Birnbaum D, Wicha MS and Dontu G: ALDH1 is a marker of normal and malignant human mammary stem cells and a predictor of poor clinical outcome. Cell Stem Cell 1: 555-567, 2007.
54. Douville J, Beaulieu R and Balicki D: ALDH1 as a functional marker of cancer stem and progenitor cells. Stem Cells Dev 18: 17-25, 2009.

55. Rasheed ZA, Yang J, Wang Q, Kowalski J, Freed I, Murter C, Hong SM, Koorstra JB, Rajeshkumar NV, He X, Goggins M, Iacobuzio-Donahue C, Berman DM, Laheru D, Jimeno A, Hidalgo M, Maitra A and Matsui W: Prognostic significance of tumorigenic cells with mesenchymal features in pancreatic adenocarcinoma. J Natl Cancer Inst 102: 340-351, 2010. 